Author: Karin Tusting

Address:

Department of Linguistics and English Language

Lancaster University

Lancaster

LA1 4YL

Tel: +44 (1)1524 510825

Email: k.tusting@lancaster.ac.uk

Full title of Article: Analysing textual trajectories: tensions in purpose and power relations

Short title of the Article (for running head): Analysing textual trajectories

Word count (all inclusive): 3194

Character count (with spaces): 21600 
Bionote: Karin Tusting is Senior Lecturer at the Department of Linguistics and English Language, Lancaster University, and is a member of the Lancaster Literacy Research Centre. Her research interests include workplace literacies, communities of practice, academic literacies and linguistic ethnography. Address for correspondence: Department of Linguistics and English Language, Lancaster University, Lancaster LA1 4YL, UK. Email: k.tusting@lancaster.ac.uk 


\section{Analysing textual trajectories: tensions in purpose and power relations}

Karin Tusting, Lancaster University, UK

\section{Introduction}

Textual trajectories are pervasive in social life. The academic workplace is full of them. While preparing this text, I have engaged in strings of interrelated email discussions around m:arking, agreeing the entextualisation of grades and feedback responses to students' written coursework for uploading to the virtual learning environment platform, in line with criteria in the departmental handbook. I have organised a conference reporting on a research project, representing two years of work with talk and text in powerpoint presentations and textuallysupported discussion activities. I have attended a media training event which coached us explicitly in how to recontextualise academic work into a one sentence interview-friendly “top line”.

There are textual trajectories everywhere in daily life, too. A call to the police non-emergency line with a concern for an elderly neighbour led me into a Question-Answer-Typing event, exactly as described in Rock's paper, which opened up new trajectories involving other local agencies. Arranging a service and road test on a three-year-old car fulfilled the requirements of national bureaucratic legal systems, and began an annual cycle of reminder correspondence with the local mechanics. Completing multiple consent forms for a residential school trip meant puzzling over the form's requirements (what counts as a “medical condition”?), while trying to figure out reasons for the duplicate information required and understand where the various similar-but-different forms would end up being sent to.

\section{Researching textual trajectories}


Given the ubiquity of textual trajectories, the body of research from professional and work contexts collected in this Special Issue is very welcome. While the papers vary in focus, they are all, as Maybin explores, rooted in shared theoretical traditions and congruent and interlinked concepts such as entextualisation, recontextualisation, resemiotisation, and dialogicality. This shared theoretical language comes from foundational theorists like Bakhtin (1935), Latour and Woolgar (1979), Linell (1998), Bauman and Briggs (1990), Bernstein (1990), Iedema (2003), and Blommaert (2005) who explore how human experience is encoded in texts dialogically, how these encodings are recontextualised in different settings and different meaning-making resources, and how these textual movements can position people within (often unequal) power relations, constructing social structure in ongoing and dynamic ways.

The move away from focusing on texts-in-themselves towards seeing them as texts-incontexts is long established, though it is framed in different ways in discourse studies, in literacy studies and in cultural studies. However, approaches to the analysis of text in context have still largely not developed ways of dealing with the dynamic nature of both texts and contexts. What the current collection offers is a range of methods of data collection, analytic tools, and specific empirical examples which provide insights not just into texts-in-context, but particularly into how texts cross and weave together different and changing contexts, achieving (or not) a range of social purposes, to the advantage of some actors and to the detriment of others. In general terms, the authors combine an ethnographic methodology with linguistic, discourse or multimodal analysis.

As Lillis and Maybin point out in their Introduction, textual trajectories have been referred to in previous work in many different ways - as chains, travels, histories, or genre suites. The common theoretical points of reference of the papers in this collection enable them to start the work of developing a shared language. This is most evident in the emergence of terms 
which work together as a typology for describing different types of trajectories. Kell’s emergent vs. scripted trajectories describes those outside and within bureaucratic systems, while Lillis’ imagined / prescribed / actual trajectories map the possibilities envisaged and experienced by people positioned differently within the system.

Analysing textual trajectories defined as a dynamic process requires, paradoxically, that the analyst select some 'fixed points' of the trajectory on which to focus. The papers in this collection do this in different ways. Rock homes in on detailed interactional processes in the interview producing the text. Lillis’ focus is broader, looking at how clusters of texts are produced together and relating these to observations of the interactions to which the texts refer. Van Hout and Burger's is the most textual in focus, inferring trajectories through close text analysis. Bezemer and Kress compare and contrast the multimodal aspects of specific interactions, and their affordances for learning. Kell locates sequences of interactions with text within a larger ethnographic storyline. These differences relate to the purposes of each piece of research. Our purposes shape where we as researchers fix these points, and whether we centralise artefacts, technologies, modes, interactions, or something else.

This fixed focal point shapes which analytic tools the researchers draw on to identify and explain specific aspects of the construction of textual trajectories in their data. Rock uses analysis of what she calls four key “discursive means” to show how a police officer makes the entextualisation process visible to witnesses, through writing-aloud; proposing wordings; reading back text; and referring to writing. The transcription conventions she uses identify when each of these means is used. In contrast, Bezemer and Kress draw on multimodal analysis to show what is gained and what is lost when pedagogic texts are materialised in sites with very different modal affordances. Van Hout and Burger use systematic coding of textual data to identify patterns in the ways “text bites” are engaged with by journalists. Kell develops a new language of description, made up of strips, nodes and participant frameworks, 
in order to relate the resemiotising and rematerialising moves she describes closely to the communities and contexts in which they are taking place.

\section{What textual trajectories can tell us}

The broader question to address here is why text trajectories are interesting to study in the first place. All the work presented here shares an underlying motivation of seeking to understand the role of materialised language - text - in social co-ordination. This is not, therefore, a model which privileges the text alone. Inherent in it is attention to the talk and interaction which constitute the dynamics of the trajectories - in Maybin's phrasing, “decentring from the text itself”. So we see, for instance, Bezemer and Kress insisting on the sign maker's engagement with texts to highlight the interpretive actions which construct trajectories; Kell locating the texts tracking activeness in the histories of engagement of the people involved; Lillis setting analysis of the case notes in the context of the interactions which gave rise to them.

By bringing together the analysis of text and interaction, we come to understand the importance of textual trajectories in terms of what Maybin calls their 'institutionally consequential' nature. The processes identified in research on textual trajectories at the micro-level are central to the creation and maintenance of social institutions and structures. This is why Maybin labels this work 'meso-level' theorising, providing a link between the micro-level of practices and the macro-level of institutions and structures, and giving purchase on how institutions really work, without abstracting and losing a grip on empirical reality. Focusing on textual trajectories provides one possible way of addressing Brandt and Clinton's (2002) appeal to move from the local to the global, while still maintaining a focus on people and their literacy practices. 
The empirical papers in this Special Issue provide a developing picture of what this 'institutional consequence’ consists of, particularly in the abstraction and distance from the individual that can be built into 'institutionally imagined' textual trajectories. Following the path of textual trajectories provides a usefully material and concrete way into analysing social practices extending in time and space which can otherwise appear abstract, making visible processes which can otherwise easily become invisible. Looking at how people use, interact with, create, and pass on texts provides a material way into processes of social practice, and often, as these papers show, to understanding the kinds of institutional co-ordination (Smith 2005) in which texts are central. As Bezemer and Kress suggest, this "render[s] visible semiotic work [...] that is often taken-for-granted, unnoticed or unaccounted for”.

Textual trajectories are constructed to fulfil social purposes, and their nature is shaped by those purposes. Bezemer and Kress' paper, for instance, explores paradigmatically interlinked texts with a common pedagogical purpose, learning and teaching surgical procedures. The texts may differ enormously in their use of different semiotic material, but the underlying purpose remains the same. However, the complexity of the social world means that, often, conflicting purposes are at play.

Lillis' paper shows the multiple purposes associated with different texts in the social work setting - providing accounts; providing evidence; and monitoring - each associated with a different longer-term textual trajectory. She shows how these purposes can clash, for instance around the case notes of an angry son's phone call, when the disparate temporal perspectives of the social worker and the manager reflect the different purposes of their roles. Sometimes these clashes between purposes can be irreconcilable and lead to communicative breakdowns, as when the son encounters the thicket of regulations around his father's discharge from hospital, against which his own wishes can hold little sway. Similar tensions are identified in Kell's account, which shows how the goals of members of the two groups are frustrated by 
the conflicting agendas of the management committee, who use shifts in textual trajectories to achieve their own purposes.

Lillis' paper also offers insights into the impacts of how purposes are designed into technological systems. The tensions between her imagined, prescribed, and actual trajectories are mirrored by the tensions between the conflicting purposes of the digital documentation system as a place for storing records, and as a means of ensuring the records are correctly put together in the first place. The pre-populated text types and templates which instantiate the institutional imaginary are in stark contrast to the control Rock's police officer has of his pencil and paper record. As academics, we can see similar tensions arising in institutional research repositories, which can act both as records of research which has been done, and as instruments to ensure that the 'right' research is being done to fulfil an institution's strategic purposes around research evaluation exercises and league table positions.

Identifying tensions around purposes takes us to the key question of power: whose purposes count? Who has the right in a given social context to 'fix' a stream of meaning-making in material form, and to move these material forms along their trajectories? If textual trajectories are, in Kell's terms, projections of meaning across time and space, it is often only certain people in certain places who have access to the resources needed to project those meanings (as Maybin discusses with reference to Bauman and Briggs 1990, and Blommaert 2001). This issue is perhaps at its most visible in Kell's paper. We see how the management committee, partly through its control of the material means of production of representation, partly through its understanding of broader textual trajectories, is able to take control of the allocation process, away from the people who have spent a year carefully recording activeness, using the resources they had to hand. We also see how the impermanence of the moment of writing on the arm causes a 'gap' in the trajectory, between the grid produced in 
the meeting and the physical allocation of sites, which actually becomes fixed only when people claim and start working in their spaces.

In Lillis' work, social workers have a degree of control over the way interactions between themselves and service users will be represented in their case notes; but this freedom is highly circumscribed by the tightly-controlled formatting provided by the electronic information system. Van Hout and Burger's paper shows the power of the journalists who, through their entextualisations and recontextualisations, frame the politicians' text bites in particular, often ironic ways. Rock's paper, in contrast, shows the institutional actor deliberately sharing his power through his patterns of interaction, enabling the witness to share in the entextualisation process.

The other crucial issue of power, evident particularly in Lillis' and in Kell's papers, relates to who has a broader understanding of where the trajectories are headed, and whether they can be turned in different directions; using Kell's terms, who understands whether and how a 'node' can be inserted into a 'strip' to change the direction of a trajectory. The more strongly 'scripted' a trajectory is, the harder it is to change it, and in Lillis' paper we see a very powerful trajectory script written into a computer recording system. The manager and the social worker have different perspectives on the trajectories which can emerge from this system; while the service user may have little understanding even of the existence of these powerful trajectories.

Power relationships also shape how people learn to create and move texts, and how they learn the longer-term consequences of the text trajectories they are engaged with. It is no accident that Rock's skilled police interviewer was drawing on years of experience in his interview technique. The social workers' professional voice, in Lillis' paper, may be initially inculcated in training, but is developed through experiences of seeing how case notes travel. Kell's 
participants did not have prior experiences of the trajectories around meetings and housing developments to draw on that would have enabled them to challenge the management committee's claims about 'very poor' activeness more directly.

\section{Addressing differences of power}

It is not enough merely to identify these trajectories, purposes and power differentials. If certain textual trajectories contribute to the abstraction and systematisation of knowledge about people, in ideologically framed ways which privilege those in power and suppress individual voices, how can this be addressed? The papers in this collection indicate several possibilities. Rock's work shows how institutional actors can take some responsibility in mitigating some of the institutional abstracting processes, through making trajectories accessible to the individuals whose words are being inserted into them - what she calls “redistribut[ing] the privilege of entextualisation”. Rock’s identification of the specific discursive moves and subtle interactions which open up frontstage entextualisation could be introduced into training programmes for police interviewers, and others. This would, of course, depend on the institution and interviewers being persuaded of the benefits of this frontstage entextualisation in the first place. Where this initial condition is in place, training in the framework of these discourse moves could provide a potentially useful 'discursive technology' (Lemke 2001) to support sharing power in the interview. This shows the importance of understanding the precise mechanics of different kinds of textual trajectories.

One of the key power differentials identified by these papers, as discussed above, is in knowledge of the extended trajectories within which specific textual interactions are inserted. Critical advocates could be trained both in these larger understandings and in ways to explicitly frontstage local entextualisation processes. It is feasible to imagine, for instance, that such critical advocacy could have made a difference to the symbolic violence 
experienced by Kell's participants. The term 'broker' is used by several of these papers, describing when Pete, Rock’s police officer, introduces his knowledge of the extended trajectory to bear in the fine details of the wordings used, or when Lillis' social worker drafts the Attendance Allowance form for the service user. The concept of a "literacy broker" is already well developed (see e.g. Lillis and Curry 2006); this work highlights the importance of such brokers having a good understanding of the textual trajectories which their brokering work forms part of.

It would, however, be a mistake to locate all the potential solutions to such power differentials in the behaviour of frontline workers. The inbuilt tensions Lillis identifies between 'imagined' and 'actual' trajectories cannot be addressed by changes in the behaviour of front-line staff, only at the level of design and management. This may not be easy. Lillis' identification of differences between managers' and social workers' temporal perspectives is not a difference in knowledge that could be addressed with training, but exposes some quite fundamental differences in interest and purpose from people with different roles and responsibilities. Her work is already action research, carried out to advise on improving the 'quality' of case recording; but she shows how complex this goal may be, as ‘quality' and 'comprehensiveness' might mean different things to people positioned differently within the system. There are likely to be tensions between the institution, seeking to improve the match between the 'actual' and 'institutionally imagined' trajectories, and frontline staff, who might prefer researchers to articulate more clearly to management why the differences exist between the two. So, addressing power differentials in textual trajectories will only really make a difference as part of a broader move to address power differentials in the system as a whole. Indeed, some institutions might be explicitly concerned to keep aspects of some text trajectories opaque to the people they relate to. 
The potential for additional research into text trajectories is clear. Building on the theoretical background, analytic tools and research focuses of the different papers in this collection, we need to continue work both to develop our understandings of the institutional and social consequences of textual trajectories, and of how it is possible to address the power and knowledge differentials that these trajectories often entail.

\section{References}

Bakhtin, Mikhail. 1981 [1935]. Discourse in the novel. In Michael Holquist (ed.) The dialogic imagination: Four essays trans. Caryl Emerson \& Michael Holquist, 259-422. Austin, Texas: University of Texas Press.

Bauman, Richard \& Charles L. Briggs. 1990. Poetics and performance as critical perspectives on language and social life. Annual Review of Anthropology 19. 59-88.

Bernstein, Basil. 1990. Class, codes and control vol. 4: The structuring of pedagogic discourse. London: Routledge.

Blommaert, Jan. 2001. Investigating narrative inequality: African asylum seekers’ stories in Belgium. Discourse and Society 12(4). 413-449.

Blommaert, Jan. 2005. Discourse. Cambridge: Cambridge University Press.

Iedema, Rick. 2003. Multimodality, resemiotization: Extending the analysis of discourse as multi-semiotic practice. Visual Communication 2(1). 29-57.

Latour, Bruno \& Steve Woolgar. 1986 [1979] Laboratory life: The construction of scientific facts, 2nd edn. New Jersey: Princeton University Press.

Lemke, Jay L. 2001. Discursive technologies and the social organization of meaning. Folia Linguistica 35(1-2). 79-97. 
Lillis, Theresa M., and Mary Jane Curry. 2006. Professional academic writing by multilingual scholars: Interactions with literacy brokers in the production of English-medium texts. Written Communication 23(1). 3-35

Linell, Per. 1998. Discourse across boundaries: On recontextualisations and blending of voices in professional discourse. In Per Linell \& Srikant Sarangi (eds.). Discourse across boundaries: On recontextualisations and the blending of voices in professional discourse. [Special Issue]. Text 18(2). 143-157.

Smith, Dorothy. E. 2005. Institutional ethnography: A sociology for people. Lanham, MD: AltaMira Press. 